\title{
PENGARUH KINERJA KELEMBAGAAN TANI TERHADAP EKSISTENSI MODAL SOSIAL PETANI KEDELAI DALAM MENDUKUNG KEBERHASILAN PROGRAM UPSUS PAJALE DI KABUPATEN LAMPUNG TIMUR
}

\author{
SEPTIANA ${ }^{1)}$, YOSINI DELIANA ${ }^{2)}$, LUCYANA TRIMO ${ }^{2)}$ \\ 1) Mahasiswa Pasca Sarjana Fakultas Pertanian Universitas Padjajaran \\ ${ }^{2)}$ Dosen Fakultas Pertanian Universitas Padjajaran \\ Email : septiaj182016@gmail.com
}

\begin{abstract}
The role of agriculture in the economic development of this country is still very important, besides being a fuel provider, this sector also contributes significantly to the development of workforce which is expected to have an increase in the change in the level of poverty. The Ministry of Agriculture has a vision and mission in alleviating poverty by rolling out various forms of programs to increase capital for farmers. Farmers who have developed their level of education, improved changes in the economic and political structure, began to understand to form a farmer group that had the goal of obtaining and obtaining mutual assistance included in the agricultural program of the government, such as the UPSUS Pajale Program. Farmers who are members of farmer groups will strengthen the ability of their groups to manage and channel the Pajale UPSUS Program assistance that requires improving farm safety consisting of indicators; the role of members of farmer groups, suitability of group services, collectivity, and resolution of local wisdom that still requires in its farming activities. The success of farmer groups can not be separated from social capital which is the main foundation that must be owned by farmers as group members. Mangkuprawira (2010) describes the support of social capital in farmers such as social norms, mutual trust, networking, cooperation, mutual relations, participation, and commitment that will be directly connected to the success of the UPSUS Pajale (soybean) program being rolled out by the government, and seen from three indicators namely; successful output, successful results, and successful benefits. The UPSB Pajale Program in East Lampung Regency is held from February to March 2019. The data used are primary and secondary data with the Mix-method research method. The sampling technique used was the Proportional Stratified Random Sampling with a total sample of 140 farmers who were members of a farmer group receiving the 2017 UPSUS Pajale Kedelai Program in East Lampung Regency. Data processing is done qualitatively and quantitatively. Data is arranged qualitatively using descriptive analysis, while quantitative data is processed using Structural Equation Modeling (SEM) analysis, which uses the LISREL 8.80 program. The results showed the value of $R 2=0.71$, which means that the second variable namely Farmer Institutional Performance and the Existence of Farmer Social Capital contributed 71 percent and was significant to the Success of the UPSUS Pajale Program in East Lampung Regency.
\end{abstract}


Keywords: Farming Institution, Existence of Social Capital, and UPSUS Pajale Program

\section{PENDAHULUAN}

Peranan pertanian dalam pembangunan ekonomi negara ini masih sangat penting terutama sebagai penyedia bahan pangan bagi rakyat Indonesia, dapat menyerap tenaga kerja dan memiliki peran sangat nyata sebagai sumber mata pencaharian penduduk karena kurang lebih 42 persen penduduk Indonesia masih berusaha di bidang pertanian serta menggantungkan hidup keluarganya dari hasil pertanian. Kementrian Pertanian mempunyai visi dalam pembangunan pertanian di Indonesia periode 2015-2019, yaitu terwujudnya kedaulatan pangan merupakan hak negara dan bangsa yang secara mandiri dapat menentukan kebijakan pangan serta memberikan hak bagi rakyat untuk menentukan sistem pangan yang sesuai dengan potensi sumber daya lokal dan menjamin kesejahteraan petani bersama keluarganya sebagai aktor utama pelaku usaha pertanian (Kementrian Pertanian, 2014).

Untuk mencapai visi tersebut, Kementrian Pertanian mengeluarkan beberapa kebijakan dan program dalam upaya membantu kesejahteraan hidup petani, salah satunya adalah Program Upaya Khusus (UPSUS) Pajale yang telah dikucurkan oleh pemerintah mulai 2015. Program ini merupakan upaya pemerintah untuk meningkatkan produksi padi, jagung, kedelai, daging sapi, tebu, cabai dan bawang merah sehingga Indonesia diharapkan dapat mengurangi keran import bahan pangan dari luar negeri. Padi dan jagung merupakan target swasembada, sedangkan kedelai, cabai, bawang merah, daging, dan gula menjadi target untuk peningkatan produksi. Kebijakan peningkatan produksi Pajale tahun 2015 tercantum dalam Peraturan Menteri Pertanian RI Nomor 03/Permentan/OT.140/2/2015 tentang Pedoman UPSUS Peningkatan Produksi Padi, Jagung, Dan Kedelai Melalui Program Perbaikan Jaringan Irigasi Dan Sarana Pendukungnya dengan menyediakan sarana produksi secara optimal, mekanisasi, teknologi dan pendampingan petani secara intensif. Peningkatan produksi tanaman pangan juga dilakukan dengan Gerakan Penerapan Pengelolaan Tanaman Terpadu (GP-PTT).

Dalam upaya memenuhi kebutuhan rata-rata kedelai pertahun di Indonesia yaitu sebesar 2,2 juta ton dan mengakhiri ketergantungan akan kedelai import yaitu sebesar 67,99\%, pada tahun 2017 kebijakan pemerintah mulai fokus pada pengembangan dan peningkatan produktivitas kedelai, baik dari kuantitas maupun kualitas dan diupayakan secara ekstensifikasi serta intensifikasi (Kementrian Pertanian, 2015). Beberapa provinsi di Indonesia yang menjadi target pengembangan dan dapat menjadi daerah sentra produksi kedelai berkelanjutan adalah Provinsi Lampung yang diharapkan dapat menyumbang 10 (sepuluh) persen dari target nasional pengembangan luas areal tanam kedelai sebesar 50.000 hektar.

Sasaran utama dari program ini adalah petani yang tergabung dalam suatu kelembagaan petani (kelompok tani), dimana pada prosesnya kelompok tani berperan dalam penyaluran bantuan paket saprodi kedelai serta alsintan ditambah sarana pendukung lainnya secara efektif pada petani sasaran yang didampingi oleh PPL (Petugas Penyuluh Pertanian) dan Petugas Pendamping Khusus Program UPSUS Pajale, sehingga diharapkan tujuan dari program ini dapat terwujud yaitu 
peningkatan produktivitas kedelai dan pada akhirnya target swasembadapun dapat tercapai. Petani yang tergabung dalam kelompok tani, akan lebih menguatkan kemampuan kelompoknya dalam mengelola dan menyalurkan bantuan Program UPSUS Pajale yang diukur dalam keberhasilan kinerja kelompok tani yang terdiri dari dari indikator: 1) peran kelompok tani, 2) kesesuaian layanan kelompok; 3) kolektivitas kelompok, 4) kearifan lokal yang masih dipertahankan oleh anggota kelompok dalam kegiatan usahataninya, dan secara tidak langsung akan terbentuk eksistensi modal sosial dalam diri petani yang menjadi modal awal dalam mendukung keberhasilan Program UPSUS Pajale tersebut. Mangkuprawira (2010) menjelaskan bahwa dukungan modal sosial yang sudah tercipta pada diri petani seperti norma social (social norms), saling percaya (trust), jaringan (network), kerjasama (cooperation), hubungan timbal balik (reciprocal relationship), partisipasi (participation), dan komitmen (commitment) akan berpengaruh secara langsung terhadap keberhasilan program-program sedang digulirkan oleh pemerintah. Keberhasilan Program UPSUS Pajale yang dapat dilihat dari tiga indikator yaitu; keberhasilan output, keberhasilan outcome, dan keberhasilan benefi. Berdasarkan pendahuluan diatas, menarik untuk dikaji tentang pengharuh kinerja kelembagaan tani terhadap eksistensi modal sosial petani kedelai dalam mendukung keberhasilan Program UPSUS Pajale di Kabupaten Lampung Timur.

\section{METODE PENELITIAN \\ Desain Penelitian}

Metode yang digunakan dalam penelitian ini adalah metode mix method dimana menurut Creswell (2014) mix-method merupakan pendekatan penelitian yang mengkombinasikan atau mengasosiasikan bentuk penelitian kuantitatif dan kualitatif. Teknik yang digunakan yaitu teknik survey dimana teknik ini berguna untuk melakukan penarikan kesimpulan secara umum/generalisasi dari sampel yang ditentukan dan berfungsi sebagai penduga terhadap populasi penduga (Iskandar, 2010). Lokasi penelitian dipilih secara sengaja (purposive) di wilayah Kabupaten Lampung Timur, tepatnya di 3 (tiga) kecamatan yaitu; 1) Kecamatan Sekampung, 2) Kecamatan Pekalongan dan 3) Kecamatan Margatiga dengan pertimbangan bahwa ketiga kecamatan ini merupakan daerah penerima alokasi terbesar pengembangan tanaman kedelai di Kabupaten Lampung Timur pada Tahun 2017. Teknik sampling yang digunakan adalah Proportional Stratified Random Sampling dengan unit analisis yang diteliti adalah petani kedelai yang sekaligus anggota kelompok tani hingga didapatkan sampel sebanyak 140 orang petani.

\section{Pengolahan dan Analisis Data}

Data diperoleh dengan menggunakan kuisioner dengan Skala Likert pengkategorian 1-5 yang diolah secara kualitatif maupun kuantitatif. Data secara kualitatif diolah dengan menggunakan analisis deskriptif, yang meliputi kinerja kelembagaan tani, identifikasi unsur eksistensi modal sosial dalam Program UPSUS Pajale, dan gambaran keberhasilan Program UPSUS Pajale khususnya kedelai di Kabupaten Lampung Timur. Sedangkan data secara kuantitatif diolah dengan menggunakan analisis persamaan Struktural Equation Modeling (SEM), yang menggunakan program LISREL 8.80. 


\section{HASIL DAN PEMBAHASAN}

\section{Kondisi Kinerja Kelembagaan Tani Kedelai}

Kinerja kelompok tani yang baik tentu akan berdampak positif pada peningkatan kesejahteraan petani anggotanya. Dari hasil penelitian, didapatkan kinerja kelembagaan tani dari setiap indikator dapat dilihat pada Tabel 1 dibawah ini :

Tabel 1. Komposisi Kinerja Kelembagaan Petani

\begin{tabular}{clc}
\hline No & \multicolumn{1}{c}{ Kinerja Kelembagaan Tani $(\mathbf{X})$} & Indeks Rata-rata \\
\hline 1 & Peran Kelompok Tani & 3.75 \\
2 & Kesesuaian Layanan Kelompok & 3.91 \\
3 & Kolektivitas Kelompok & 3.27 \\
4 & Kearifan Lokal & 3.56 \\
\hline Indeks Nilai Rata-Rata & $\mathbf{3 . 6 0}$ \\
\hline Kategori & Baik \\
\hline
\end{tabular}

Sumber : Output LISREL Hasil Olahan Peneliti

Dari Tabel 1, dapat dilihat bahwa secara keseluruhan indeks rata-rata variabel Kinerja Kelembagaan Tani (X) masuk dalam kategori "baik" dengan nilai 3,60, dimana untuk indikator Kesesuaian Layanan Kelompok yang memiliki indeks rata-rata tertinggi yaitu sebesar 3,91 dan masuk dalam kategori "baik". Sedangkan nilai indeks Kolektivitas Kelompok Tani yaitu sebesar 3,27 dan masuk dalam kategori "cukup baik", nilai ini bisa dikatakan masih kurang dibandingkan dengan ketiga sub variabel lainnya dalam mendukung kinerja kelembagaan tani. Rendahnya kolektivitas kelompok tani didaerah penelitian terkait dengan Pemerintah sebagai pemberi Program UPSUS pajale yang belum dapat memberikan jalinan kerjasama yang saling menguntungkan antara petani dan pedagang kedelai lokal serta belum adanya jaminan harga terbaik pagi kedelai lokal yang dihasilkan petani.

\section{Kondisi Eksistensi Modal Sosial Petani dalam Program UPSUS Pajale}

Dalam variabel Eksistensi Modal Sosial petani terdapat 7 (tujuh) indikator yang menjadi unsur pendukung seperti yang digambarkan pada Tabel 2. dibawah ini :

Tabel 2. Komposisi Eksistensi Modal Sosial Petani Kedelai

\begin{tabular}{clc}
\hline No & \multicolumn{1}{c}{ Esistensi Modal Sosial Petani (Y) } & Indeks Rata-rata \\
\hline 1 & Norma Sosial/Social Norms & 3.78 \\
2 & Saling Percaya/Trust & 3.38 \\
3 & Jaringan/Network & 3.54 \\
4 & Kerjasama/Cooperation & 3.76 \\
5 & Hub. Timbal Balik/Reciprocal Relationship & 3.76 \\
6 & Partisipasi/Partisipation & 3.99 \\
7 & Komitmen/Commitment & 3.76 \\
\hline Nilai Indeks Rata-Rata & $\mathbf{3 . 7 1}$ \\
\hline Kategori & Baik \\
\hline
\end{tabular}

Sumber : Output LISREL Hasil Olahan Peneliti

Dari Tabel 2. diketahui bahwa secara keseluruhan nilai indeks rata-rata dari ketujuh indikator unsur pendukung Eksistensi Modal Sosial petani sebesar 3,71 dan masuk dalam kategori "baik". Dapat dilihat bahwa untuk indikator Partisipasi mendapatkan indeks rata-rata tertinggi diantara yang lainnya, yaitu 
sebesar 3.99 kondisi ini didukung karena ddaerah penelitian sebagian besar merupakan wilayah perdesaan dengan nilai saling menghargai serta rasa ingin tau akan informasi teknologi pertanian masih sangat besar, sehingga berpengaruh pada tingkat partisipasi petani dalam mengikuti dan berperan aktif pada setiap kegiatan atau program yang didapat oleh kelompok taninya. Hal ini sesuai dengan apa yang dikemukaan oleh Hasbullah (2006) bahwa kelompok yang dibangun atas dasar kesamaan orientasi dan tujuan dengan ciri pengelolaan organisasi yang lebih modern akan memiliki tingkat partisipasi anggota yang lebih baik dan rentang jaringan yang lebih luas. Partisipasi petani ditunjukkan dengan seringnya terlibat atau diikutsertakan dalam kegiatan yang ada didalam kelompok tani ataupun kelembagaan pertanian lainnya. Partisipasi petani dalam kelembagaan timbul karena tumbuhnya kesadaran untuk membangun kerjasama dan kepercayaan sehingga mendorong penguatan kelembagaan yang mereka ikuti. Partisipasi individu petani dalam kelembagaan akan menghasilkan pengalaman belajar yang berharga bagi petani, hal ini sesuai dengan dengan pendapat Founier (2002) pembangunan partisipasi dapat dijadikan sebuah strategi keberlanjutan kehidupan (suitainable livelyhood) yang menjadi elemen dasar untuk pembentukan modal sosial dan intervensi dalam pengurangan kemiskinan juga mempercepat/membentuk jejaring yang luas didalam kelompok-kelompok masyarakat.

Trust atau rasa saling percaya merupakan bentuk keinginan untuk mengambil risiko dalam hubungan sosial yang didasari perasaan yakin bahwa akan melakukan sesuatu seperti yang diharapkan dan akan bertindak dalam suatu pola tindakan yang saling mendukung dan tidak merugi kan diri serta kelompoknya (Hasbullah, 2006). Rasa saling percaya dan harapan yang dimiliki oleh petani terhadap Program UPSUS Pajale pada dasarnya sangat besar, dimana petani percaya bahwa program ini dapat membantu petani keluar dari zona kemiskinan serta selalu mendukung agar program ini dapat berjalan dengan baik, terutama untuk komoditas padi dan jagung.

Pada komoditas padi dan jagung petani sudah membuktikan bahwa dengan bantuan Program UPSUS Pajale, usahatani mereka mendapatkan keuntungan yang cukup besar, namun untuk komoditas kedelai pada periode Tahun 2017 masih banyak mengalami kegagalan karena waktu datangnya bantuan yang tidak tepat waktu maupun sebab lainnya. Kegagalan yang dialami petani tersebut tidaklah menjadikan petani "kapok", dan masih berharap pemerintah memberikan bantuan komoditas kedelai dengan tetap memperhatikan hasil evaluasi pada periode bantuan sebelumnya agar untuk selanjutnya lebih baik dan tepat guna.

\section{Kondisi Lapangan Keberhasilan Program Upsus Pajale}

Berdasarkan hasil penelitian keberhasilan Program UPSUS Pajale komoditas kedelai petani yang mendapatkan bantuan pada Tahun 2017 dapat dilihat pada Tabel 3 dibawah ini : 
Tabel 3. Komposisi Keberhasilan Program UPSUS Pajale (Kedelai) tahun 2017

\begin{tabular}{clc}
\hline No & Keberhasilan Program UPSUS (Y2) & Indeks Rata-Rata \\
\hline 1 & Keberhasilan Output & 3.90 \\
2 & Keberhasilan Outcome & 3.25 \\
3 & Keberhasilan Benefit & 2.80 \\
\hline Nilai Indeks Rata-Rata & $\mathbf{3 . 3 2}$ \\
\hline Kategori & Cukup Baik \\
\hline
\end{tabular}

Sumber : Output LISREL Hasil Olahan Peneliti

Dari tabel 3. diatas dapat dilihat bahwa nilai indeks rata-rata dari variabel Keberhasilan Program UPSUS Pajale kedelai ini secara keseluruhan mendapatkan nilai sebesar 3,32 dan masuk dalam kategori "cukup baik". Sedangkan dari ketiga indikator pendukung keberhasilan program, keberhasilan output yang memegang komposisi paling besar atau dominan dengan indeks rata-rata sebesar 3.90 dan masuk dalam kategori "baik". Keberhasilan output ini tentu saja tidak terlepas dari proses penyaluran bantuan program yang sudah dilakukan dengan baik oleh masing-masing kelompok tani penerima program. Dengan adanya bantuan Program UPSUS ini secara tidak langsung sudah manjadi sarana kelompok tani dalam melaksanakan fasilitasi penguatan kapasitas anggota kelompoknya dalam berbagai hal, misalnya kapasitas kerjasama antara sesama anggota maupun pihak luar (pengrajin tempe/tahu, kios pertanian, pedagang pengumpul kedelai,) juga meningkatnya kapasitas jaringan yang makin besar dalam hal teknologi dan informasi pertanian.

Dari variabel keberhasilan program tersebut, selain indikator keberhasilan output terdapat 2 (dua) indikator lain yaitu keberhasilan outcome dan keberhasilan benefit yang masih memiliki indeks nilai rata-rata rendah yaitu masing-masing 3.25 dan 2.80 dan masuk dalam kategori "cukup baik". Kedua indikator ini harus lebih diperhatikan bahkan ditingkatkan, dimana salah satu yang menjadi kendala adalah jumlah petani yang mendapatkan bantuan Program UPSUS Pajale Kedelai pada dasarnya sudah cukup banyak dan hampir merata pada semua kelompok tani sasaran, namun pada kenyataannya karena rasa trauma akan kegagalan usahatani kedelai yang menyebabkan berkurangnya pendapatan petani pada priode bantuan sebelumnya membuat petani tersebut enggan menanam kedelai lagi, sehingga secara otomatis jumlah petani yang mau menanam komoditas kedelai dengan bantuan Program UPSUS inipun makin berkurang.

Hasil pengolahan data SEM LISREL 8.8 menunjukkan bahwa, tidak ada nilai yang dominan atau hasilnya relatif sama. Pada variabel Kinerja Kelembagaan Tani yang memiliki nilai tertinggi adalah indikator kesesuaian layanan kelompok dengan nilai 3.91. Berdasarkan hasil analisis data, variabel ini memberikan pengaruh nilai yang signifikan terhadap variabel Eksisitensi Modal Sosial Petani dalam Program UPSUS Pajale. Adanya pengaruh ini sesuai dengan nilai yang didapatkan oleh variabel Eksisitensi Modal Sosial Petani dalam Program UPSUS Pajale yang terbesar adalah pada indikator partisipasi dengan nilai 3.99. Kedua hal ini terdapat hubungan saling mempengaruhi dimana antara tersalurnya bantuan saprodi Program UPSUS Pajale pada petani tidak terlepas dari Kinerja Kelembagaan Tani yang sudah baik dan tertata diantaranya kelompok tani tersebut sudah memiliki aturan/norma tertulis maupun yang tidak tertulis dan sudah disepakati bersama antar sesama anggota, selain itu kelompok tani jg sudah memiliki manajemen administrasi yang baik sehingga segala sesuatunya lebih 
tertata dan tercatat. Berdasarkan variabel Kinerja Kelembagaan Tani dan Eksisitensi Modal Sosial Petani dalam Program UPSUS Pajale yang sebagian unsurnya sudah berjalan dengan baik, hal ini berpengaruh pada Keberhasilan Program UPSUS Pajale, khusunya indikator keberhasilan output yang dicirikan dengan terlaksananya seluruh proses penyaluran bantuan UPSUS Pajale yang sekaligus menjadi sarana fasilitasi penguatan kapasitas kelompok tani yang petani ikuti.

Hasil penelitian juga menunjukkan masih terdapat beberapa indikator yang memiliki nilai indeks rata-rata cukup rendah dan perlu menjadi perhatian semua pihak untuk acuan evaluasi dan meningkatkan kinerjanya agar apa yang menjadi tujuan Program UPSUS Pajale ini dapat tercapai. Pada variabel Kinerja Kelembagaan Tani yang memiliki nilai terendah adalah indikator kolektivitas kelompok dengan nilai 3.27 dan masuk dalam kategori "cukup baik". Dengan demikian, pada variabel Kinerja Kelembagaan Tani, yang harus lebih ditingkatkan dan diperbaiki adalah hal-hal yang berkaitan dengan kolektivitas atau jalinan kerjasama antara petani dengan pihak lain terutama dengan para pedagang pengumpul kedelai dan industri tahu/tempe dalam hal harga yang saling menguntungkan.

Pada variabel Eksisitensi Modal Sosial Petani dalam Program UPSUS Pajale yang memiliki nilai terendah adalah pada indikator saling percaya/trust dengan nilai 3.38 dan masuk dalam kategori "cukup baik". Dalam hal ini, petani memiliki krisis kepercayaan pada pemerintah berkaitan dengan belum adanya jaminan harga bagi kedelai lokal yang petani hasilkan, selain itu petani juga mengalami kesulitan memasarkan hasil kedelai lokal karena harus bersaing dengan kedelai import, dimana pedagang dan pengrajin tahu/tempe lebih menyukai kedelai import karena selain harganya yang lebih murah kualitasnya pun lebih baik dengan bentuk kedelai yang lebih besar. Selain yang berkaitan dengan pemasaran, yang menjadi kendala utama petani pada periode bantuan kedelai tahun 2017 yaitu masih banyaknya petani yang mengalami kegagalan, yang disebabkan mulai dari datangnya bantuan yang waktunya tidak tepat, benih kedelai yang kurang baik dan belum berspesifik lokasi, serangan hama dan penyakit kedelai yang tinggi, sehingga berakibat pada produktivitas kedelai yang rendah dengan rata-rata sebesar 5,6 kuintal/hektar dari target produktivitas sebesar $14,6 \mathrm{kuintal} / \mathrm{hektar}$.

Selanjutnya pada variabel Keberhasilan Program UPSUS Pajale Kedelai yang perlu ditingkatkan lagi adalah pada indikator keberhasilan benefit dengan nilai 2.80 dan masuk dalam kategori "cukup baik". Kondisi diatas, tentu saja berimbas pada pendapatan yang diperoleh petani. Pada musim tanam kedelai Tahun 2017, rata-rata petani mengalami gagal panen kedelai karena serangan hama dan penyakit yang tinggi, tetapi ada pula yang masih bisa mendapatkan hasil dan dijual ke pasar walaupun dengan harga yang kurang baik. Adapun persentase pendapatan petani sebelum dan sesudah mendapatkan Program Bantuan UPSUS Pajale kedelai pada tahun 2017 ditampilkan pada Tabel 4 dibawah ini: 
Tabel 4. Komposisi Pendapatan Petani Sebelum dan Sesudah menerima Program UPSUS Kedelai Tahun 2017

\begin{tabular}{lcc}
\hline \multicolumn{1}{c}{ Pendapatan } & Rata-rata Pendapatan/MT (Rp) & Berkurang (\%) \\
\hline Sebelum & $4,722,214$ & 33.1 \\
Sesudah & $3,159,035$ & \\
\hline Sub &
\end{tabular}

Sumber : data primer diolah, 2019

Pada Tabel 4 diatas dapat dilihat bahwa, sebelum mendapatkan bantuan Program UPSUS Pajale kedelai Tahun 2017, mayoritas petani masih mengusahakan lahannya dengan menanam padi, jagung serta singkong. Dari ketiga komoditas tersebut petani masih bisa memperoleh pendapatan rata-rata bersih per musim tanamnya lebih besar dari setelah mendapatkan bantuan,, yang pada saat itu mengalami kegagalan. Persentase berkurangnya pendapatan petani dari sebelum dan sesudah menanam kedelai bantuan program tersebut mencapai 33,1 persen. Persentase berkurangnya pendapatan petani tersebut sebagian besar dialami oleh petani yang menanam kedelai dilahan basah atau persawahan dengan pola tanam monokultur, sedangkan untuk petani yang menanam dilahan kering masih bisa sedikit mendapatkan hasil dari pola tanam tumpang sari.

Untuk menjawab dari tujuan penelitian ini, hasil pengujian hipotesis hubungan kausal dan nilai t-hitung dengan menggunakan analisis pengujian dengan tingkat signifikansi $5 \%$ sehingga menghasilkan critical t-value sebesar \pm 1.96. Hipotesis hasil pengujian diterima apabila $t$-value yang didapat $\geq 1.96$, sedangkan hipotesis tidak didukung apabila t-value yang didapat $<1.96$ yang dapat dilihat pada Gambar 1 dibawah ini:

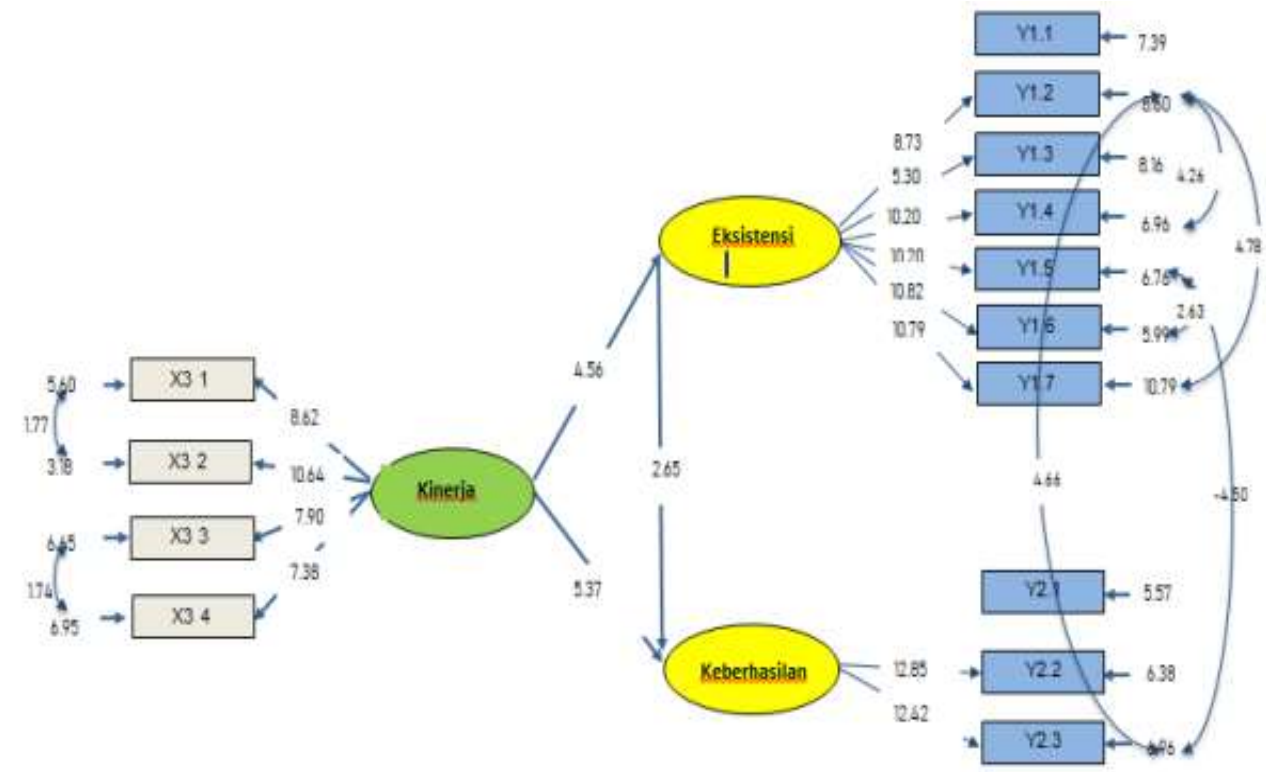

Sumber : Output LISREL Hasil Olahan Peneliti

\section{Gambar 1. Model Struktural (t-values)}

Dari Gambar 1 diatas, analisis pengujian hipotesis dijabarkan dalam pernyataan yang mendukung pada penelitian ini, yaitu :

a. Eksistensi Modal Sosial dalam Program UPSUS Pajale dipengaruhi oleh Kinerja Kelembagaan Tani 
Berdasarkan hasil pengolahan data dari model struktural, diperoleh hasil $t$ value dari Eksistensi Modal Sosial dalam Program UPSUS Pajale yaitu sebesar 4,56 atau lebih besar dari 1.96, maka dapat disimpulkan bahwa variabel Eksistensi Modal Sosial dalam Program UPSUS Pajale dipengaruhi secara signifikan oleh Kinerja Kelembagaan Tani, hal ini dapat diterima dan disimpulkan bahwa semakin baik Kinerja Kelembagaan tani penerima Program UPSUS Pajale dalam menjalankan tugas dan fungsinya secara langsung menunjukkan akan semakin baik pula Eksistensi Modal Sosial dalam Program UPSUS yang dimiliki oleh petani penerima program tersebut.

b. Keberhasilan Program Program UPSUS Pajale dipengaruhi oleh Kinerja Kelembagaan Tani

Berdasarkan hasil pengolahan data dari model struktural, diperoleh hasil output berupa $t$-value sebesar 5,37 atau lebih besar dari 1.96, maka dapat disimpulkan bahwa variabel Keberhasilan Program UPSUS Pajale dipengaruhi secara signifikan oleh Kinerja Kelembagaan Tani yang ada didaerah penelitian. Dengan demikian hal ini dapat diterima dan disimpulkan bahwa Keberhasilan Program Program UPSUS Pajale dapat tercapai dengan baik bila didukung oleh Kinerja Kelembagaan Tani yang baik pula.

c. Keberhasilan Program Program UPSUS Pajale dipengaruhin oleh Eksistensi Modal Sosial dalam Program UPSUS

Berdasarkan hasil pengolahan data dari model struktural, diperoleh hasil output berupa $t$-value sebesar 2,65 atau lebih besar dari 1.96, maka dapat disimpulkan bahwa variabel Keberhasilan Program UPSUS Pajale dipengaruhi secara signifikan oleh Eksistensi Modal Sosial dalam Program UPSUS Pajale. Dengan demikian dapat disimpulkan bahwa Keberhasilan Program UPSUS Pajale dapat dicapai dengan baik bila didukung oleh Eksistensi Modal Sosial dari Petani penerima Program UPSUS Pajale UPSUS Pajale yang baik pula.

Besarnya pengaruh Kinerja Kelembagaan Tani (X1) dan Eksistensi Modal Sosial Petani dalam Program UPSUS Pajale $\left(\mathrm{Y}_{1}\right)$, juga menunjukkan nilai yang signifikan terhadap Keberhasilan Program UPSUS Pajale $\left(\mathrm{Y}_{2}\right)$ dimana berdasarkan hasil perhitungan secara kausalitas besarnya pengaruh itu adalah sebagai berikut:

Keberhas $=0.28 *$ Eksisten $+0.49 *$ Kinerja,

$\begin{array}{lll}(0.11) & (0.091) \quad(0.064)\end{array}$

$2.65 \quad 5.37 \quad 4.56$

Errorvar. $=0.29, \mathrm{R}^{2}=0.71$

Dari Structural Form Equation di atas dapat dilihat bahwwa nilai $\mathrm{R}^{2}$ yang didapat sebesar 0,71, hal ini menunjukkan bahwa kedua variabel Kinerja Kelembagaan Tani dan Eksistensi Modal Sosial Petani memberikan pengaruh yang besar serta signifikan terhadap Keberhasilan Program UPSUS Pajale yaitu sebesar 71 persen dan masuk dalam kategori pengaruh sangat kuat. Dapat disimpulkan bahwa Kinerja Kelembagaan tani dan Eksistensi Modal Sosial dalam Program UPSUS Pajale dapat menjelaskan 71 persen varian dari Keberhasilan Program UPSUS Pajale, sedangkan sisanya dipengaruhi oleh faktor lain yang tidak diamati dalam penelitian ini. 


\section{KESIMPULAN DAN SARAN}

\section{Kesimpulan}

Dalam penelitian ini, kesimpulan yang dapat diambil adalah sebagai berikut:

1. Kinerja Kelembagaan Tani memegang pengaruh yang signifikan terhadap Eksistensi Modal Sosial petani dalam mendukung keberhasilan Program UPSUS Pajale di Kabupaten Lampung Timur;

2. Eksistensi Modal Sosial petani dalam Program UPSUS Pajale dapat mempengaruhi Keberhasilan Program UPSUS Pajale kedelai bila didukung oleh Kinerja Kelembagaan Tani yang baik.

3. Besarnya pengaruh Kinerja Kelembagaan Tani dan Eksistensi Modal Sosial dalam mendukung Keberhasilan Program UPSUS Pajale (kedelai) yaitu sebesar 71 persen.

Saran

Berdasarkan hasil penelitian dan pembahasan disarankan hal-hal sebagai berikut :

1. Perlu Adanya campur tangan pihak terkait (Pemerintah) sebagai fasilitator yang menjembatani kerjasama atau kolektivitas antara petani dan pedagang kedelai atau pengrajin (tahu/tempe).

2. Jaminan harga kedelai dipasaran perlu segera mendapatkan perhatian, agar petani percaya bahwa pemerintah dapat berpihak pada kepentingan petani dan tidak merasa dirugikan.

3. Bantuan alsintan maupun benih kedelai harus lebih diperhatikan baik dari segi waktu datangnya maupun kualitas benih dan mengutamakan azas bottom up dari petani agar bantuan yang diterima dapat lebih tepat sasaran.

\section{DAFTAR PUSTAKA}

Creswell, J. (2014). Research Design Pendekatan Kualitatif, Kuantitatif dan Mixed. Yogyakarta: Pustaka Pelajar.

Founier, F. (2002). Social Capital Formation in Poverty Reduction; Which Role For Civil Society and The State? Introduction in The Symposium Entitled Social Capital Formation In Poverty Reduction. Unisco.

Hasbullah, J. (2006). Sosial Capital (Menuju Keunggulan Budaya Manusia Indonesia). Jakarta: MR. United Prees.

Iskandar. (2010). Metodologi Penelitian Pendidikan dan Sosial. Jakarta: GP.

Kementrian Pertanian. (2014). Visi dan Misi Kementrian Pertanian Indonesia Tahun 2015-2019. Jakarta: Kementrian Pertanian.

Kementrian Pertanian. (2015). Peraturan Mentri Pertanian No. 03 Tahun 2015

Tentang Pedoman Upaya Khusus (UPSUS) Peningkatan Produksi Pajale

Melalui Program Perbaikan Jaringan Irigasi dan Sara Pendukungnya

Tahun Anggaran 2015. Jakarta: Kementrian Pertanian.

Mangkuprawira, S. (2010). Strategi Peningkatan Kapsitas Modal Sosial dan Kualitas Sumberdaya Manusia Pendamping Pembangnan Pertanian. Forum Penelitian Agro Ekonomi Vo.1 28 No. 1. 